\title{
Proceeding
}

Performance Analysis Workshop, 2 - 5 April 2013, Alicante, Spain

\section{A comparative analysis of visual strategy in elite and amateur handball goalkeepers}

\author{
JESUS RIVILLA-GARCÍA ${ }^{1} \quad$, ALEJANDRO MUÑOZ¹, IGNACIO GRANDE ${ }^{1}$, MERCEDES SANCHÍS \\ ALMENARA2 ${ }^{2}$ JAVIER SAMPEDRO ${ }^{1}$ \\ ${ }^{1}$ Department of Sports, Faculty of Physical Activity and Sports Sciences, Polytechnic University of Madrid, Spain \\ ${ }^{1}$ Institute of Biomechanics, Valencia, Spain
}

\begin{abstract}
Rivilla-García J, Muñoz A, Grande I, Sanchís, M, Sampedro J. A comparative analysis of visual strategy in elite and amateur handball goalkeepers. J. Hum. Sport Exerc. Vol.8, No. Proc3, pp. S743-S753, 2013. The aim of the present study was to analyze the visual strategies prior to a throw from 7 metres in elite and amateur handball goalkeepers. To this end we analyzed the visual fixations in number and order of 10 goalkeepers (29.7 \pm 5.4 years; $14.7 \pm 8.6$ years of experience), 3 elite and 7 amateurs, during the life size projection of 14 different throws, made by different players. During each throw the movement of the eyeballs, the dilation of the pupil (pupillometry) and the subject's blinking were recorded thanks to a technological system which permitted eye tracking with high speed cameras, and the subsequent presentation of the visual data for each action studied. The elite goalkeepers performed a greater number of visual fixations than the amateur goalkeepers, revealing large and significant differences. Equally the priority zones observed were differed, with the amateur goalkeepers fixating more on the thrower's face, and the elite goalkeepers paying more attention to the area of the arm/ball. It can therefore be inferred that elite goalkeepers have a greater perceptive capacity and also use different visual strategies from the amateur goalkeepers. Key words: ANTICIPATION, VISUAL BEHAVIOUR, PERCEPTION, THROW.
\end{abstract}

Corresponding author. Department of Sports, Faculty of Physical Activity and Sports Sciences, Polytechnic University of Madrid, 28040, Madrid, Spain.

E-mail: jesus.rivilla@upm.es

Performance Analysis Workshop, 2 - 5 April 2013, Alicante, Spain

JOURNAL OF HUMAN SPORT \& EXERCISE ISSN 1988-5202

(c) Faculty of Education. University of Alicante

doi:10.4100/jhse.2013.8.Proc3.21

VOLUME 8 | Proc3 | 2013 | S743 


\section{INTRODUCTION}

Visual strategy has been considered for years as an important variable for sports performance (Abernethy \& Russell, 1987; Williams et al., 1999; Van Den Tillar, 2004) as it greatly influences anticipation, a fundamental quality in many sports specialities (Sánchez 1992; Abernethy \& Zawi, 2007).

Anticipation is the capacity to foresee what will occur on the basis of stimuli prior to the action, which permits gaining time and therefore, being more efficient (Moreno et al., 1998; Guzmán \& García-Ferriol, 2002). In the sports context, players have to react quickly to the stimuli from their surroundings (Bideau et al., 2004). Consequently, anticipation in sport refers to the perception of relevant information and the consequent decision making in the shortest time possible. Bearing in mind the enormous quantity of stimuli and information offered by the surroundings, the player has to elaborate visual strategies to discard the irrelevant information and select the relevant information in the shortest time possible.

Traditionally motor actions have been analyzed with respect to three progressive processes: perception, decision making and execution of the movement (Abernethy, 1996; Abernethy et al., 1996). Prior to the execution of the movement, also known as the motor solution (Malho, 1969), the situation must be analyzed, followed by the elaboration of a mental solution and the selection of the most suitable response. Therefore, the success of the action begins to be generated before the execution, depending to a great extent on the cognitive processes performed beforehand.

Many of the determinant actions in team sports, and especially in handball, are characterized by their speed and require the players to be able to predict what will occur as reaction strategies will prevent them from being on time (Roca, 1991; Antúnez \& García, 2008). In fact, the ability to predict future actions based on the movements of other players is considered one of the most important abilities for practising sporting activities (Gutiérrez-Davila et al., 2011). Thus, several studies have demonstrated that some players are capable of anticipating the trajectory of an object thrown by an opponent on the basis of the stimuli of the surroundings which provide sufficient information to enable them to act efficiently (Lidor et al., 1998; Debanne, 2003). These stimuli which contribute relevant information on the subsequent action of the opponent are called pre-cues or indicators (Moreno et al., 1998).

In this sense, goalkeeping in handball demands a high level of anticipation as, by observing the prior actions of the thrower, the goalkeeper has to be able to predict the trajectory of the ball. Thus, the goalkeeper must use the information perceived to elaborate anticipatory strategies for their interventions (Párraga et al., 2001), and to this end needs to catch the stimuli or pre-cues which enable them to quickly analyze the information and react in the shortest time possible (Antúnez \& García, 2008).

Several studies have found differences in the perceptive strategies among players of different competitive levels. In tennis, Goulet et al. (1989) found that expert tennis players focussed on different body areas of their opponents from beginners, during their service action. Gill (1994) observed that expert tennis players were able to carry out precise predictions on their opponent's stroke $600 \mathrm{~ms}$ before they hit the ball. Following this line of study, Del Campo et al. (2012) showed that expert and novice tennis players used different visual strategies for detecting the pre-cues of movement, and also had different reaction and response skills. In football, Savelsbergh et al. (2002) reported that expert and novice goalkeepers possessed different visual strategies for detecting pre-cues of movement, and more specifically, stated that the expert goalkeepers used a more efficient pattern which involved a lesser number of fixations but of longer duration, something which seems to coincide with other sports modalities (Bard et al., 1981). 
The competitive level seems to be determinant with regard to areas of visual fixation, according to studies on football, which have found differences between expert and amateur goalkeepers (Savelsbergh et al., 2005). However, this anticipation requires the player to be able to recognize the pre-cues in the opponent (Féry \& Crognier, 2001) to be able to use them to systemize their response and create specific motor patterns (García, 2010).

Based on the supreme importance of the goalkeeper's perception mechanisms as well as on the possible differences that there may be among players of different competitive levels, and bearing in mind the scarcity of studies on this aspect in handball, we considered it necessary to gain greater insight into the strategies of visual fixation in handball goalkeepers. The aim of the present study was thus to analyze the number and areas of visual fixation of handball goalkeepers from different competitive levels.

\section{MATERIAL AND METHODS}

\section{Sample}

The sample was made up of a non random sample of ten handball goalkeepers (age: $29.7 \pm 5.4$ years; experience as handball goalkeepers: $14.7 \pm 8.6$ years). Three of them were professional goalkeepers who competed in the highest category of clubs and seven were non professional goalkeepers who played in amateur categories. It is interesting to note that one of the goalkeepers was a clear example of the highest competitive level as he not only competed at the highest national and international levels but had also won the most prestigious international trophies with his club and national team.

\section{Procedure}

To analyze the visual strategy of handball goalkeepers from different levels and the number of fixations during the throws, videos were shown of throws from 7 metres to different areas of the goal performed by players with different characteristics: right handed, left handed, elite and amateur throwers. The goalkeepers stood in front of the screen where the 14 throws from 7 metres were projected. Before starting the test each subject performed three trials to familiarize them with the equipment and the dynamics of the study.

The test sequence, which was repeated for the 14 throws was adapted from Piras \& Vickers, 2011; Williams et al., 1996:

1) Before each throw the subjects saw a slide with an initial sentence indicating that they had to pay full attention (Figure 1a).

2) Projection of a static image of the beginning of the throw (3s) to prepare for the action.

3) Projection of the throwing action where the video stopped and finished just before the ball left the player's hand (Figure 1b).

The reason for stopping the image at that moment was to analyze the visual strategies prior to the goal shot. All the subjects saw the 14 throws by players with different characteristics to different areas of the goal (Figure 1c). The goalkeepers were unaware of the characteristics of the thrower, the throw or the area aimed at beforehand. 


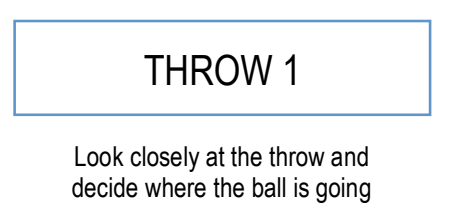

(a)

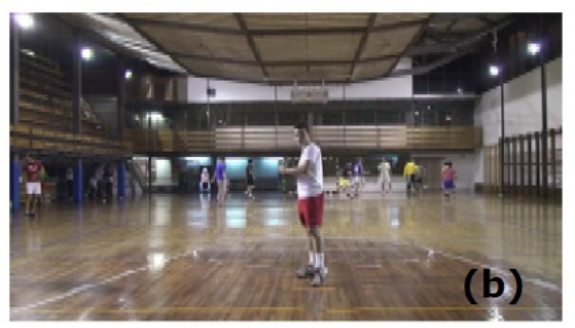

To where the ball went?
\begin{tabular}{|c|c|c|}
\hline 1 & 2 & 3 \\
\hline 4 & 5 & 6 \\
\hline 7 & 8 & $9(\mathrm{c})$ \\
\hline
\end{tabular}

Figure 1. Test sequence

Thanks to a technological system of eye tracking (TobiiX120®), data on the following variables were recorded for each throw:

- Fixation: the instant in which the eyes remain relatively still to focus on a concrete area of the scene. These are very short periods of time, frequently lasting only 200 to 350 milliseconds (ms). In this study visual fixation was considered as all the time periods of over $200 \mathrm{~ms}$ in which the eyes remained fixed on a point.

- The number of total fixations: number of fixations performed by the subject during the projection of the image.

- Average time for each fixation: the average duration of each fixation.

- Area of interest: areas which had been identified as a priority observation area according to information offered by the goalkeepers in surveys prior to the experiment.

Using this information 5 areas of interest for the study were generated in the image (Figure 2) and variables were determined for each of the areas of interest: time at the first fixation in each area of interest, area chosen for the first fixation, areas chosen for the second and third fixation, total duration of the fixation by area of interest, number of fixations by area of interest, ratio of the duration of the fixation by area of interest, ratio of the number of fixations by area of interest, average duration of the fixation by area of interest.

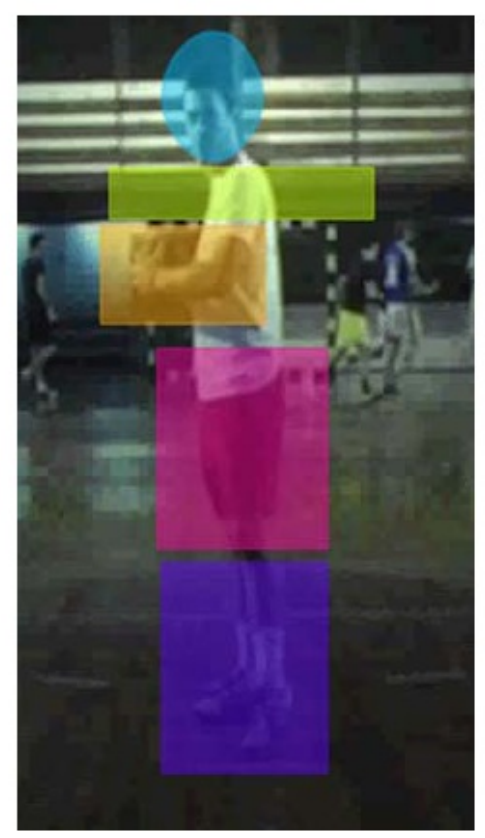

Figure 2. Research zones 


\section{Material}

The throws from 7 metres were filmed with a video camera (Sony PJ650VE Full HD) located in the centre of the goal and which permitted observation of all the movements of the thrower from the normal viewpoint of the goalkeeper. All the throws were filmed from this same position. Subsequently the video clips were processed with the Adobe Premiere Pro CS6 video editing programme, selecting the video frames at the beginning and the end as well as the sequences needed for the projection.

The projection of the throws in front of the goalkeepers was made using a $4 \times 4 \mathrm{~m}$ screen, thus simulating an actual throw.

The analysis of the visual fixations of the goalkeeper required the visual monitoring of each one of the throws. This was done with a Tobii X120® Eye Tracker which uses high speed cameras to track the movement of the eye balls, the dilation of the pupils (pupillometry) and the blinking of the subject, among other factors. The information recorded by the programme made it possible to follow the eyes of the goalkeepers and to create maps which marked the places they looked at for the longest time as well as getting information on the visual trajectories which corresponded to each of the throws.

\section{Analysis}

This investigation followed a descriptive quantitative methodology as it aimed to look in greater depth at the data obtained. The descriptive analysis was performed using standard statistical methods. A t test for independent samples was used to analyze the number of fixations. The data collected were processed with the SPSS software programme version 11.5.

\section{RESULTS}

Firstly, significant differences were found between the number of visual fixations for the amateur goalkeepers and for the professionals $(p<0.01)$. The following figure $(3)$ clearly illustrates the superiority of the professional goalkeepers with regard to the number of fixations during the phase prior to the throw.

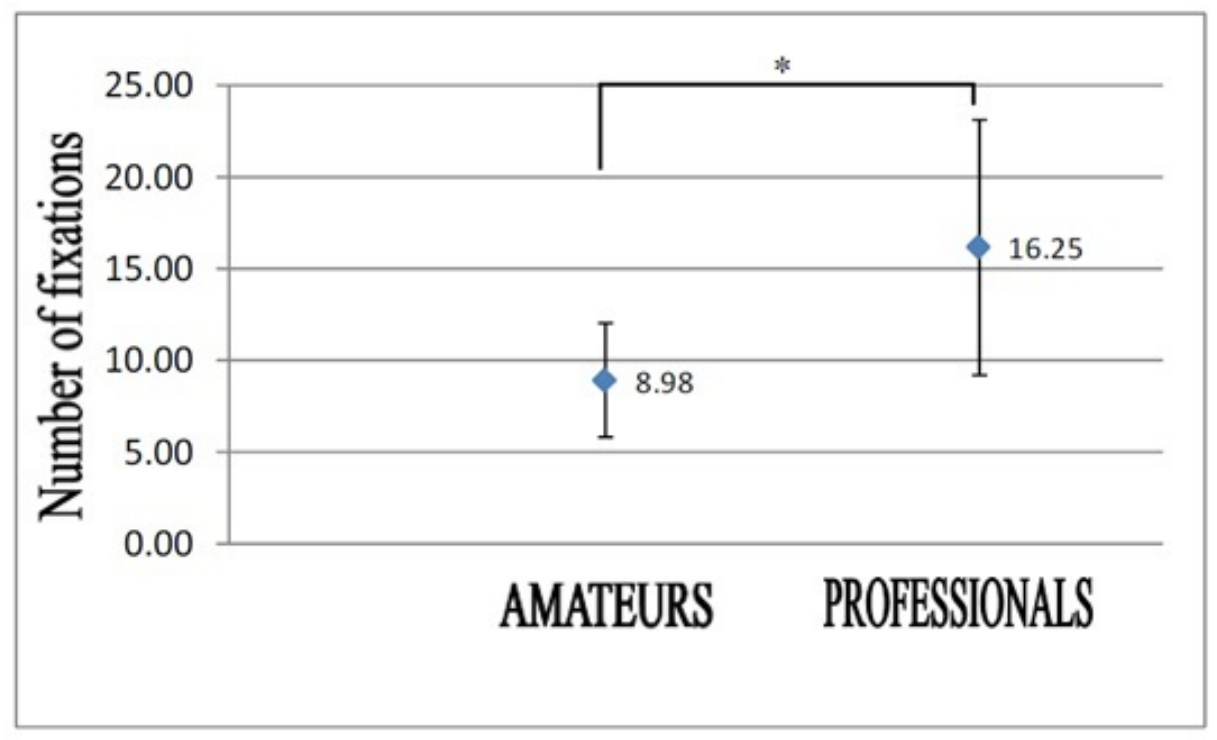

Figure 3. Number of fixations during the phase prior to the throw 
Differences were also observed between the elite goalkeepers and the amateurs with regard to the number of total fixations per area. More precisely, the amateur goalkeepers prioritized their visual fixations in three body areas of the thrower during the $7 \mathrm{~m}$ throw: legs/feet, hips/thighs and face (Figure 4). In contrast the professional goalkeepers focussed to a greater extent on the area of hips/thighs and, to a lesser extent, on the legs/feet and arm/ball (Figure5).

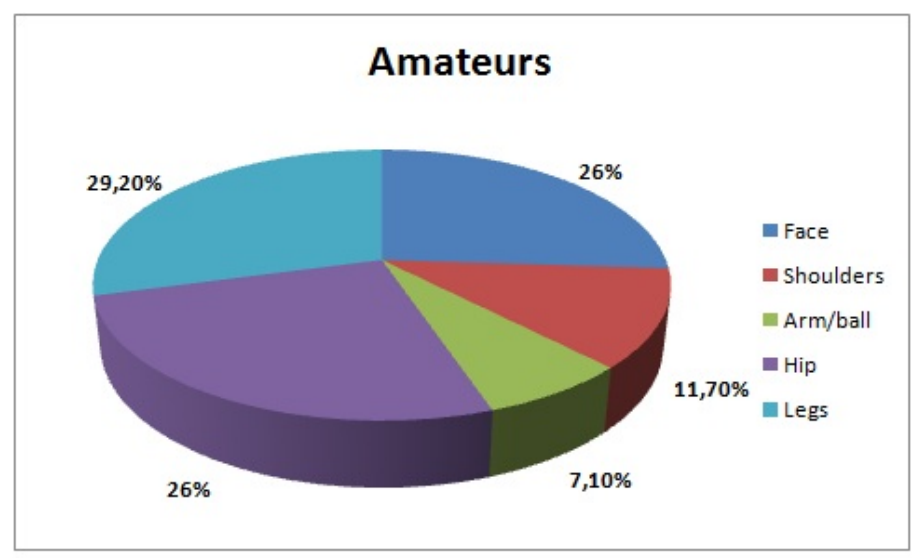

Figure 4. Body areas of the thrower during the $7 m$ throw (a)

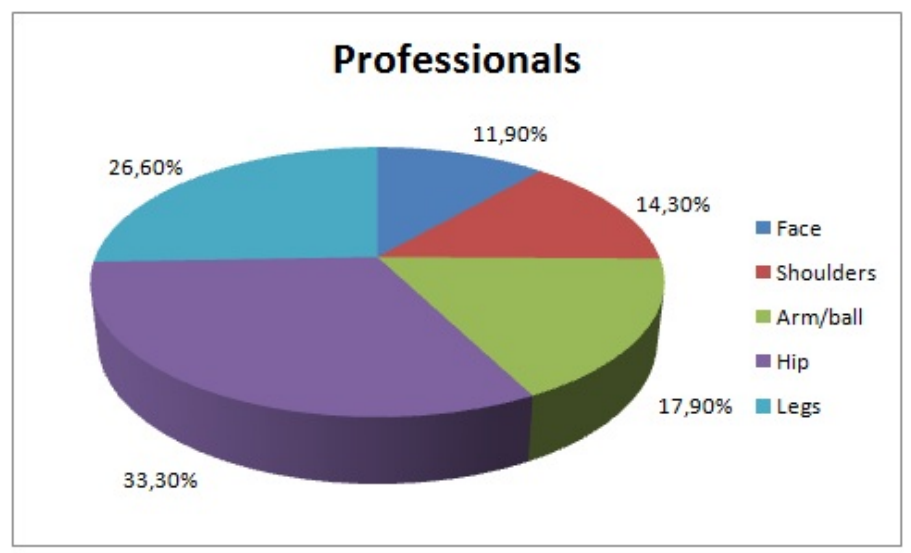

Figure 5. Body areas of the thrower during the $7 m$ throw (b)

With regard to the area of fixation by order, the amateur players had three preferred areas for the first fixation: feet/legs, thighs/hips and face (Figure 6). However, in the second fixation they did not observe the face so much (Figure 7) but concentrated more on the legs and the position of the feet. Lastly their third fixation was predominantly on the face (Figure 8). In contrast, the professional players' first fixation was mainly on the feet, legs and hips (Figure 9), and then they focussed on the arm and ball (Figure 10-11). By percentage, there is was a considerable difference between elite goalkeepers and the amateurs with regard to last fixation on the face, being much greater in the amateur goalkeepers (40\%) than in the professionals $(16 \%)$. 


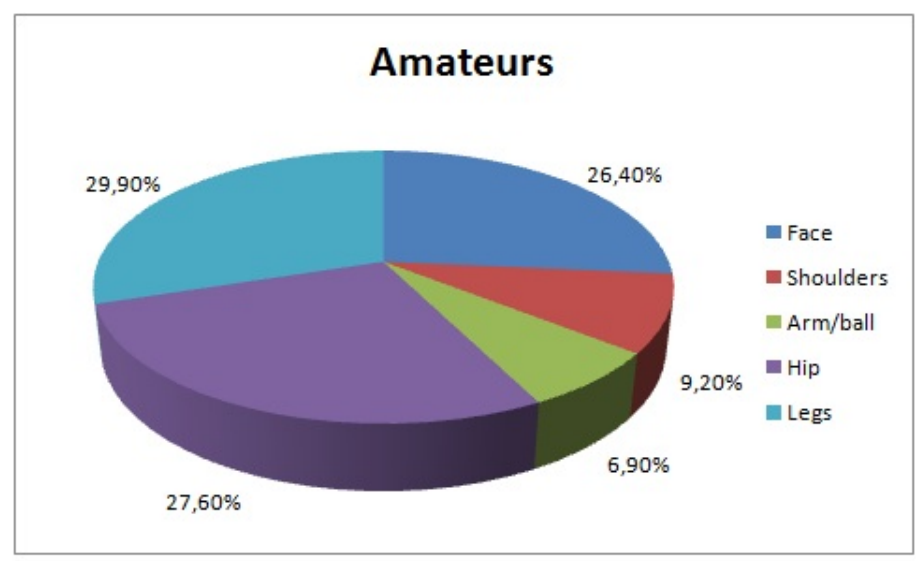

Figure 6. Body areas of the thrower during the $7 m$ throw (c)

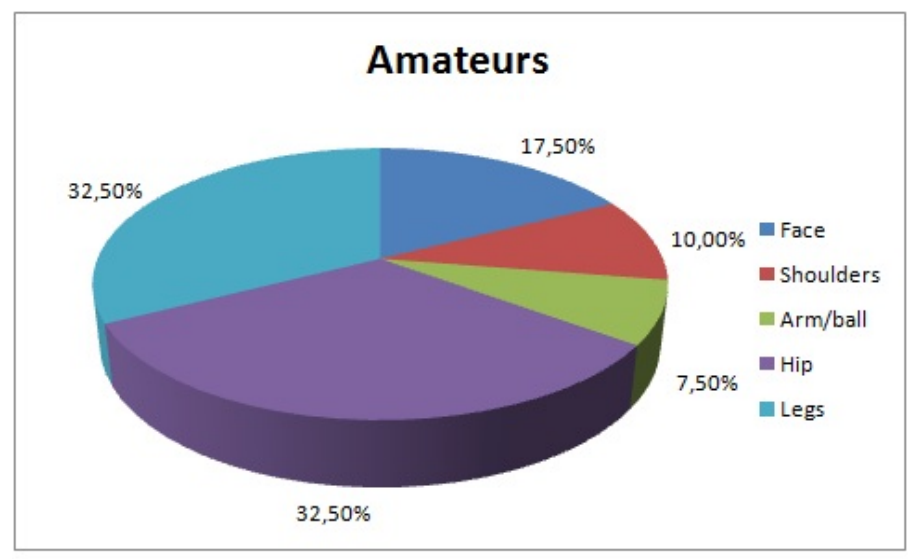

Figure 7. Body areas of the thrower during the $7 m$ throw (d)

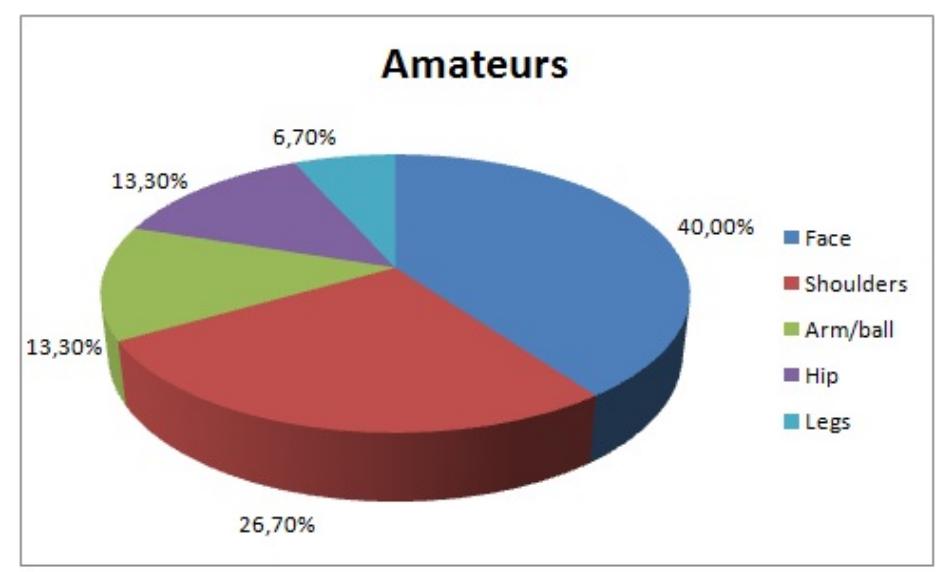

Figure 8. Body areas of the thrower during the $7 \mathrm{~m}$ throw (e) 


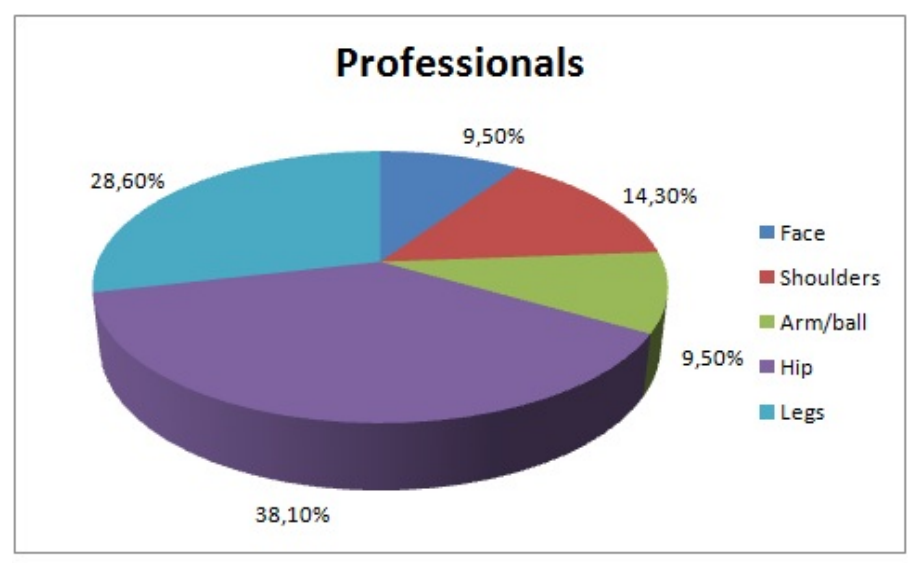

Figure 9. Body areas of the thrower during the $7 m$ throw (f)

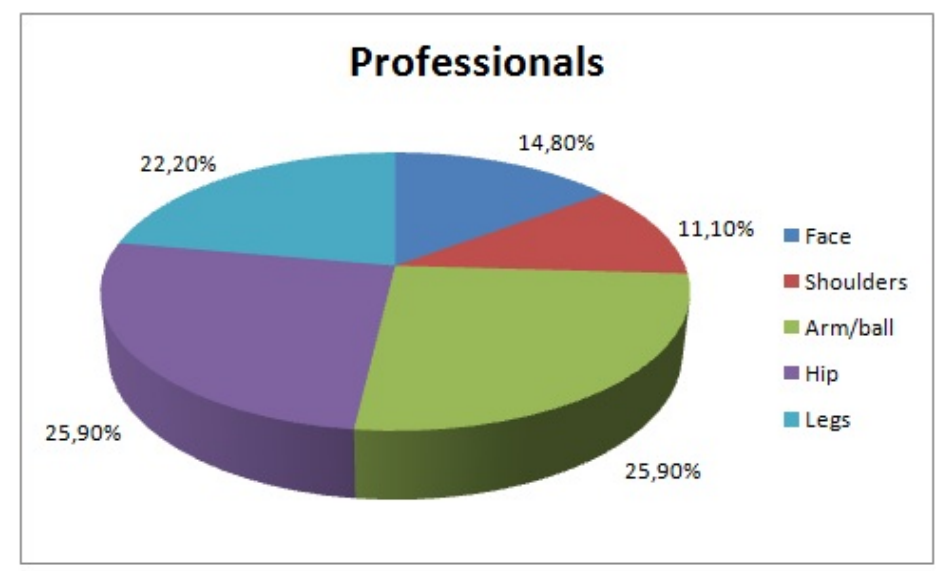

Figure 10. Body areas of the thrower during the $7 m$ throw $(g)$

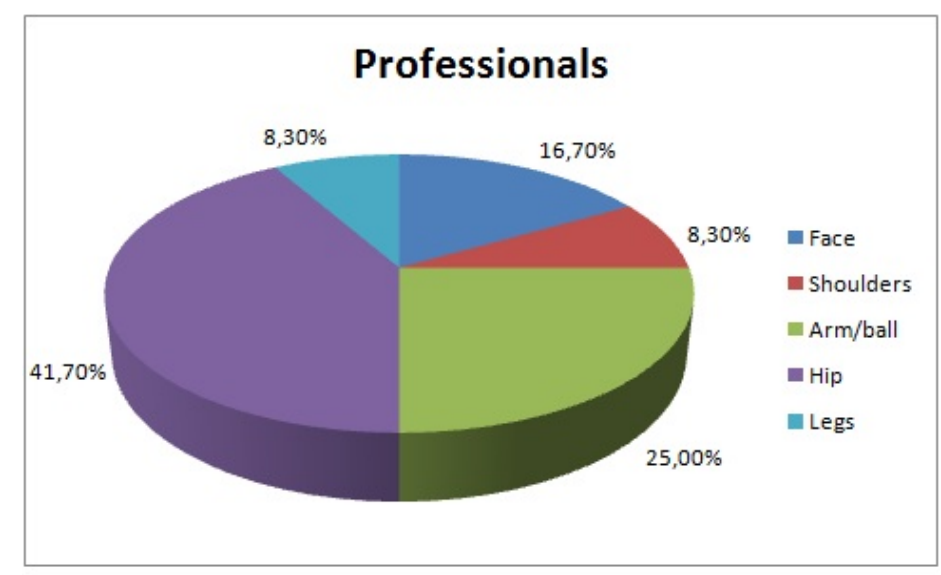

Figure 11. Body areas of the thrower during the $7 m$ throw (h) 


\section{DISCUSSION}

Firstly it is noteworthy that the professional goalkeepers perform a greater number of fixations than the amateurs. This means that elite goalkeepers have a greater perceptive capacity and are able to perceive more stimuli from the surroundings. The reason for this difference may be in the fact that the elite goalkeepers accumulate a great deal of experience of throws and thus increase their capacity to perceive information.

Furthermore, the results obtained permit us to state that the visual strategies of the elite goalkeepers differ from those of the amateurs. As well as performing a greater number of fixations, the goalkeepers from a higher competitive level focussed more on the arm and ball while the amateurs focussed more on the face of the thrower. This may be due to the importance, which professional goalkeepers attribute to the body areas near the ball as well as the differences in the trajectory of the throw as a function of the movement of the arm in the throw. On the other hand there did not seem to a difference among goalkeepers with regard to the fixations on the hips and legs of the thrower, which occupied more than half the total fixations in both cases.

The differences with regard to the perceptive capacity in favour of the elite goalkeepers seem to confirm the need for the goalkeepers to perceive the greatest quantity of information to be able to elaborate action strategies (Párraga et al., 2001; Del campo et al., 2012).

Although there are few studies on this topic in handball, the differences in perception according to the competitive level coincide with the results obtained in tennis (Goulet et al., 1989; Del Campo et al., 2012), football (Williams et al., 1994; Savelsbergh et al., 2005) and other modalities (Bard et al., 1981). The differences in visual behaviour as a function of competitive level may be due to several factors like experience in training and matches, instruction, game practices and perception. More precisely it could be inferred that novice players are less able to analyze the sports context and identify movement patterns in situations where time is lacking (Williams et al., 1999).

\section{CONCLUSIONS}

The competitive level is determinant in prior visual strategy for a $7 \mathrm{~m}$ throw. More precisely, elite players possess a greater capacity to perceive stimuli from their surroundings in terms of number and areas of fixation.

Furthermore, amateur players not only perceive a lesser quantity of information prior to the throw but they also focus their attention on different areas - face and lower limbs - from those chosen by the elite goalkeepers - arm/hand, shoulder and hip.

\section{REFERENCES}

1. ABERNETHY B, KIPPERS V, MACKINNON LT, NEAL RJ, HANRAHAN S. The biophysical foundations of human movement. Melbourne: Macmillan, 1996.

2. ABERNETHY B, RUSSELL DG. The relationship between expertise and visual search strategy in a racquet sport. Hum Movement Sci.1987; 6:283-319.

3. ABERNETHY B. Training the visual-perceptual skills of athletes: Insights from the study of motor expertise. Am J Sport Med. 1996; 24(SUPPL.):S89-S92. 
4. ABERNETHY B. Visual search strategies and decision-making in sport. Int J Sport Psychol. 1991; 22:189-210.

5. ABERNETHY B, ZAWI K. Pickup of Essential Kinematics Underpins Expert Perception of Movement Patterns. J Motor Behav. 2007; 39(5):353-367.

6. ANTÚNEZ A, GARCÍA M. La especificidad en la condición física del portero de balonmano. Ebalonmano.com: revista digital deportiva. 2008; 4(1):5-12.

7. BARD C, GUEZENNE I, PAPIN JP. 'Escrime: Analyze de l'exploration visuelle'. Medicine du Sport. $1981 ; 15: 117-26$.

8. BIDEAU B, MULTON F, KULPA R, FRADET L, ARNALDI B, DELAMARCHE P. Using virtual reality to analyze links between handball thrower kinematics and goalkeeper's reactions. Neurosci Lett. 2004; 372:119-122.

9. DEBANNE T. Activité perceptive et décisionelle du gardie de but de handball lors de la parade: les saviors d'experts. Staps. 2003: 3(62):43-58.

10. DEL CAMPO VL, REINA R, SABIDO R, MORENO FJ. Comportamiento visual y respuesta de reacción en tenis según el tipo y dirección del golpe. Apunts. Educación física e deportes. 2012; 107:61-68.

11. FÉRY Y, CROGNIER L. On tactical significance of games situations in anticipating ball trajectories in tennis. Res Q Exercise Sport. 2001; 72(2):143-149.

12. GARCÍA P. Entrenamiento táctico del portero de balonmano en la iniciación. Una propuesta de trabajo. Madrid: Comunicación presentada al Congreso de balonmano base, 2010.

13. GILL D. Expert-novice differences in cue utilisation in 'oncourt' squash performances - practical. Australian Squash Coach. 1994; 2(2):15-19.

14. GOULET C, BARD C, FLEURY M. Expertise differences in preparing to return a tennis serve: A visual information processing approach. J Sport Exercise Psy. 1989; 11:382-398.

15. GUTIERREZ-DAVILA M, ROJAS FJ, ORTEGA M, CAMPOS J, PARRAGA J. Anticipatory strategies of team-handball goalkeepers. J Sport Sci. 2011; 29(12):1321-1328.

16. GUZMÁN JF, GARCÍA FERRIOL A. La anticipación defensiva en los deportes de equipo: Un estudio de la importancia otorgada a sus variables. Apunts. Educación física e deportes. 2002; 69:37-42.

17. LIDOR R, ARGOV E, DANIEL S. An exploratory study of perceptual-motor abilities of women: Novice and skilled players of team handball. Percept Motor Skill. 1998; 86(1):279-288.

18. MALHO F. La acción táctica en el juego. La Habana: Vigot, 1969.

19. MORENO FJ, OÑA A, MARTíNEZ M. La anticipación en el deporte y su entrenamiento a través de preíndices. Revista de Psicología del Deporte. 1998; 2:205-213.

20. PÁRRAGA JA, SÁNCHEZ A, OÑA A. Importancia de la salida del balón y de la precisión como parámetros de eficacia en el lanzamiento en salto a distancia en balonmano. Apunts. Educación física e deportes. 2001; 66:44-51.

21. ROCA J. Percepción: usos y teorías. Apunts. Educación física e deportes. 1991; 25:9-14.

22. SÁNCHEZ F. Bases para una didáctica de la Educación física y el deporte. Madrid: Gymnos, 1992.

23. SAVELSBERGH GJP, VAN DER KAMP J, WILLIAMS AM, WARD P. Anticipation and visual search behaviour in expert soccer goalkeepers. Ergonomics. 2005; 48(11):1686-1697.

24. SAVELSBERGH GJP, WILLIAMS AM, VAN DER KAMP J, WARD P. Visual search, anticipation and expertise in soccer goalkeepers. J Sports Sci. 2002; 20:279-287.

25. VAN DEN TILLAAR R. A force-velocity relationship and coordination patterns in over arm throwing. J Sport Sci Med. 2004; 3(4):211-219. 
26. WILLIAMS AM, DAVIDS K, BURWITZ L, WILLIAMS JG. Visual search strategies in experienced and inexperienced soccer players. Res Q Exercise Sport. 1994; 65(2):127-35.

27. WILLIAMS AM, DAVIDS K, WILLIAMS JG. Visual perception and action in sports. London: E. \& F.N. Spon, 1999. 